\title{
Evaluation of the Effectiveness of Metabolites of Bacterial Strains Bacillus thuringiensis against Human Influenza Virus A/Aichi/2/68 (H3N2) In Vitro and In Vivo I. S. Andreeva ${ }^{1}$, N. A. Mazurkova ${ }^{1}$, A. I. Zakabunin'², L. I. Puchkova ${ }^{1}$, E. I. Filippova ${ }^{1}$, and A. S. Safatov ${ }^{1}$
}

Translated from Byulleten'Eksperimental'noi Biologii i Meditsiny, Vol. 169, No. 5, pp. 583-586, May, 2020 Original article submitted January 13, 2020

\begin{abstract}
The morphological and physiological characteristics of Bacillus thuringiensis strains were analyzed and conditions for obtaining culture fluid with maximum yield of secreted RNases were determined. Zymographic analysis showed that culture fluid of $B$. thuringiensis strains along with low-molecular-weight (15-20 kDa) RNases contained enzymes with a molecular weight $\sim 55 \mathrm{kDa}$ and their content depended on the duration and conditions of culturing. Preparations based on $B$. thuringiensis culture fluid were effective against human influenza virus $\mathrm{A} / \mathrm{Aichi} / 2 / 68$ (H3N2). In experiments on mice infected with 10 LD50 influenza virus strain A/Aichi/2/68 (H3N2), we selected effective variants of preparations based on culture fluid of $B$. thuringiensi strains for preventive administration that provided reliable protection of infected animals (protection coefficient 50\%), close to that of the reference drug Tamiflu.
\end{abstract}

Key Words: Bacillus thuringiensis; antiviral activity; human influenza virus

High spread of influenza and short-term immunity against this infection leading to repeated epidemics characterized by severe consequences for the patients' health and working capacity require the development and search for new protective preparations against influenza infection. Ribonucleases (RNases) are the most important enzymes of RNA metabolism exhibiting high specificity to certain nucleotide sequences and structures [9]. Special attention is paid to biological effects of ribonucleases such as antiviral and cytotoxic activities $[5,11]$. Almost all studied species of bacilli, including $B$. thuringiensis $(B t)$, possess ribonucleases that exhibit a wide range of biological effects against pro- and eukaryotic cells [4,14]. Ribonucleases produced by bacilli exhibited antiviral activity against RNA-containing viruses such as polio, tick-borne

${ }^{1}$ State Research Center of Virology and Biotechnology Vector, Federal Service for Surveillance on Consumer Rights Protection and Human Wellbeing, Koltsovo, Novosibirsk Region; ${ }^{2}$ Institute of Chemical Biology and Fundamental Medicine, Siberian Division of the Russian Academy of Sciences, Novosibirsk, Russia. Address for correspondence: andreeva_is@vector.nsc.ru. I. S. Andreeva encephalitis, and rabies viruses [3,7,13]. Ribonucleases are widely used in practice to study the structure and function of nucleic acids and as drugs in antiviral therapy and oncology $[5,12]$.

It should be noted that $B t$ RNases are poorly studied; there are several domestic publications on the isolation of extracellular RNase [8]. In 2016, isolation of highly-purified RNase named BALNASE (B. altitudinis RNase) from $B$. altitudinis, previously known as $B$. thuringiensis var. subtoxicus B_388 was described [10]. The inhibition of human influenza virus $\mathrm{A} / \mathrm{Aichi} / 2 / 68$ (H3N2) and avian influenza virus A/chicken/Kurgan/05/2005 (H5N1) on MDCK tissue culture by water-soluble metabolites of $B t$ strains was reported. The observed inhibition of reproduction of RNA-containing influenza viruses $\mathrm{A} / \mathrm{H} 5 \mathrm{~N} 1$ and $\mathrm{A} / \mathrm{H} 3 \mathrm{~N} 2$ in cell culture can be explained by the presence of bacterial RNases in the preparations of the studied $B t$ strains [1,2].

Our aim was testing of metabolites of $B$. thuringiensis strains containing secreted RNases for the presence of antiviral activity against human influenza virus in experiments in vitro and in vivo. 


\section{MATERIALS AND METHODS}

Bt strains Gi-443, Gi-466, and Cb-527 from The Collection of Bacteria, Bacteriophages, and Fungi, State Research Center of Virology and Biotechnology Vector were used to investigate antiviral activity in this research. Fermentation of the studied strains was performed under aerated conditions using a standard LB medium (Difco) and TYGG and TYGS media differing from LB by higher concentrations of trypton and yeast extract as well as the composition and concentration of salts and carbohydrates. The composition of TYGG medium (g/liter): 9.27 trypton, 5 yeast extract, $3 \mathrm{NaCl}$, 0.2 glucose, and 5 glycerin; composition of TYGS medium (\%): 2.1 trypton, 2.5 yeast extract, 1 glucose, $0.04 \mathrm{Na}_{2} \mathrm{HPO}_{4}, 0.01 \mathrm{CaCl}_{2}, 0.03 \mathrm{MgSO}_{4} \times 7 \mathrm{H}_{2} \mathrm{O}$, $0.01 \mathrm{MnSO}_{4}$, and $0.3 \mathrm{NaCl}$.

To obtain samples of bacterial preparations, the strains were cultured on a thermostated rocker for $18 \mathrm{~h}$ at $30^{\circ} \mathrm{C}$ followed by centrifugation of the obtained culture medium (CF) for $20 \mathrm{~min}$ at $8000 \mathrm{rpm}$ on a JA-21 centrifuge (Beckman). Supernatant was sterilized by successive ultrafiltration through Whatman filters with pore sizes of 0.45 and $0.2 \mu$. The obtained samples of filtrates and biomass were stored before use at $-20^{\circ} \mathrm{C}$.

RNase activity in CF was assayed by measuring the content of acid-soluble products formed during hydrolysis of high-polymeric yeast RNA $(1 \mathrm{mg} / \mathrm{ml})$. The amount of the enzyme catalyzing the formation of 1 unit of absorption $(260 \mathrm{~nm})$ of acid-soluble products over $1 \mathrm{~h}$ under selected conditions $\left(37^{\circ} \mathrm{C}, 50 \mathrm{mM}\right.$ HEPES (pH 8.0) in the presence of $2 \mathrm{mM} \mathrm{MgSO}_{4}$ and $\mathrm{CaCl}_{2}$ ) was considered as a unit of the enzyme activity. Electrophoresis of CF proteins under fully denaturing conditions was performed by the Laemmli method using Precision Plus Protein Standards unstained (BioRad) as the molecular mass markers. Zymography of RNases was performed in $15 \%$ polyacrylamide gel under denaturing conditions as described previously [13].

Human influenza virus A/Aichi/2/68 (H3N2) from The Microorganism Collection of the State Research Center, Virology and Biotechnology Vector was used to assess the antiviral efficacy of the obtained preparations. Each variant of the experiment was conducted in three parallel repeats; the mean values were used for the analysis. Toxicity and antiviral activity of the preparations were tested in continuous MDCK cell culture obtained from The Cell Culture Collection, State Research Center of Virology and Biotechnology Vector.

For evaluation of antiviral activity of the preparations in vitro, 10 -fold dilutions (from 1 to 8 ) of the virus-containing allantois fluid (VCAF) were prepared using RPMI-1640 medium containing $2 \mu \mathrm{g} / \mathrm{ml}$ trypsin. Then, $100 \mu \mathrm{CF}$ of $B t$ strain in selected dilution and
$100 \mu \mathrm{VCAF}$ (dilutions 1-8) were added to the monolayer culture of MDCK cells. The cells were incubated for 2 days at $37^{\circ} \mathrm{C}$ and $5 \% \mathrm{CO}_{2}$ in a TS-1/80 SPU thermostat. In 2 days, cytopathogenic effect (CPE) was recorded in each well under an inverted microscope and the presence of the virus in the culture medium was detected by hemagglutination assay (HA) with $1 \%$ suspension of chicken red blood cells.

In in vivo experiments, the protective properties of the studied preparations against influenza virus A/Aichi/2/68 (H3N2) were studied on outbred ICR mice (body weight 15-17 g; nursery of State Research Center of Virology and Biotechnology Vector). The therapeutic-preventive scheme was used: solutions of the preparations were administered orally $(200 \mu \mathrm{l} /$ mouse) $1 \mathrm{~h}$ before infection. The mice were infected intranasally under light ether anesthesia by administering a total of $40 \mu \mathrm{l}$ of the corresponding dilution of influenza virus strain A/Aichi/2/68 (H3N2) into both nostrils in a dose of $10 \mathrm{LD}_{50}$. Then, the solutions of the test preparations were administered 2 times a day for 5 days (including the day of infection). The animals were observed over 16 days; the survival rate in the experiment and control, protection coefficient, and the mean life expectancy (ALE) of mice were determined. The number of animals that lived a certain number of days after infection before death and the number of animals that survived were taken into account in determining ALE in each experimental group. The next day after the last death among infected mice (day 16) was considered as the maximum ALE for survivors.

The results were processed statistically by standard methods using Statistica 6.0 software (StatSoft, Inc.); significance of differences was evaluated at $p \leq 0.05$ [6]. In experiments for evaluation of the therapeutic-preventive effects of the preparations, the proportion of survivors in groups was compared using the $\chi^{2}$ test. ALE values are presented as $M \pm S D$ and compared using nonparametric Mann-Whitney $U$ test [6].

\section{RESULTS}

Under identical culturing conditions, $B t$ strain cells growing on TYGG, TYGS, and LB media differed by physiological parameters. Thus, Bt Gi-443, Bt Gi-466, and $B t \mathrm{Cb}-527$ strains after 24-h incubation on TYGG and LB media were presented by vegetative cells with homogeneous cytoplasm, without signs of degradation and formation of endospores, while culturing on TYGS medium with microelements promoted sporulation process. The synchronized physiological state of vegetative cells and the absence of destroyed cells were observed when $B t$ cells were cultured under aerated conditions at $30^{\circ} \mathrm{C}$ for $18 \mathrm{~h}$. The highest yield of 

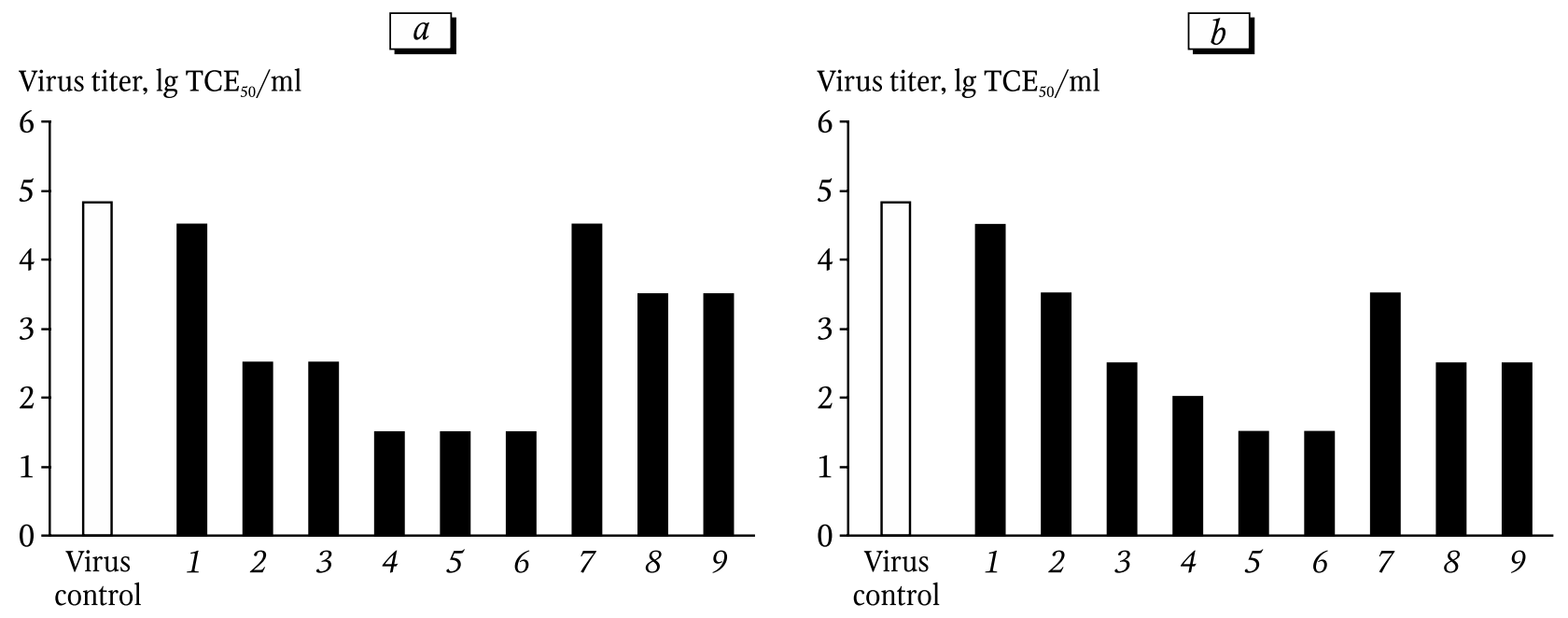

Fig. 1. Reduction of the infectivity of influenza virus $A / A i c h i / 2 / 68$ (H3N2) under the influence of samples of CF of Bacillus thuringiensis strains depending on strain culturing medium. TYGG medium: CF of Bt Cb-527 strain (1), CF of Bt Cb-466 strain (2), CF of $B t$ Cb-443 strain (3); TYGS medium: CF of Bt Cb-527 strain (4), CF of Bt Cb-466 strain (5), CF of Bt Cb-443 strain (6); LB medium: CF of $B t$ Cb-527 strain (7), CF of Bt Cb-466 strain (8), CF of Bt Cb-443 strain (9).

RNases in the medium ( $\sim 370-400$ act. units $/ \mathrm{ml})$ was recorded when $B t$ strains were cultured on TYGG medium, the maximum production of extracellular $\mathrm{RN}$ ases being achieved after 10-12 h of culturing. On TYGS and LB media it was maintained up to $24 \mathrm{~h}$, after which activity of CF decreased, while on TYGG medium, the maximum concentration of RNases was maintained up to $50 \mathrm{~h}$ of culturing.

Antiviral activity of $B t$ strains differed depending on the strain and composition of the nutrient medium (Fig. 1,a). It should be noted that storage of tat -(18$20)^{\circ} \mathrm{C}$ for 4 months (observation period) did not led to changes the toxic properties or loss of activity (Fig. $1, b)$.
Analysis of the protective properties of preparations against influenza virus A/Aichi/2/68 (H3N2) showed that sample No. 1 (CF of $B t$ strain $\mathrm{Cb}-527$ on TYGG medium) and sample No. 2 (CF of $B t$ strain Cb-527 on TYGS medium) administered to mice before and over 5 days after infection with influenza virus provided significantly higher survival rate: $60 \%$ vs $10 \%$ in the control (without the preparation) (Table 1).

In the infected reference group (infection and administration of commercial anti-influenza drug Tamiflu), $60 \%$ animals survived, which significantly differed from the corresponding parameter in the control. ALE of mice treated with preparations Nos. 1 and 2,

TABLE 1. Protective Properties of Preparations Based on CF of Bacillus thuringiensis Strains against Influenza Virus A/Aichi/2/68 (H3N2) in Experiments on Mice $(n=10 ; M \pm S D)$

\begin{tabular}{|c|c|c|c|c|c|c|}
\hline \multirow{3}{*}{ Sample } & \multirow{3}{*}{$\begin{array}{c}\text { Bacillus } \\
\text { thuringiensis } \\
\text { strain }\end{array}$} & \multirow{3}{*}{$\begin{array}{l}\text { Culture } \\
\text { medium }\end{array}$} & \multicolumn{4}{|c|}{ Survival rate of mice infected with 10 LD $_{50}$ influenza virus } \\
\hline & & & \multicolumn{2}{|c|}{ survived mice } & \multirow{2}{*}{$\mathrm{PC}, \%$} & \multirow{2}{*}{ ALE } \\
\hline & & & $\mathrm{n}$ & $\%$ & & \\
\hline No. 1 & Cb-527 & TYGG & 6 & $60^{*}$ & 50 & $12.5 \pm 4.6^{+}$ \\
\hline No. 2 & & TYGS & 6 & $60^{*}$ & 50 & $12.1 \pm 5.1^{+}$ \\
\hline No. 3 & & LB & 4 & 40 & 30 & $10.0 \pm 5.3$ \\
\hline No. 4 & Gi-466 & TYGG & 5 & 50 & 40 & $11.1 \pm 5.2$ \\
\hline No. 5 & & TYGS & 0 & 0 & 0 & $7.1 \pm 1.5$ \\
\hline No. 6 & & LB & 3 & 30 & 20 & $9.5 \pm 4.6$ \\
\hline Tamiflu & - & - & 6 & $60^{*}$ & 50 & $12.4 \pm 4.7^{+}$ \\
\hline Control (no preparations) & - & - & 1 & 10 & - & $6.9 \pm 3.6$ \\
\hline
\end{tabular}

Note. PC: protection coefficient. $p \leq 0.05$ in comparison with the control ( ${ }^{*} X^{2}$ test and ${ }^{+}$Mann-Whitney $U$ test). 
and with Tamiflu were comparable and significantly differed from that in the control (Table 1).

In studies with samples No. 3 ( $B t$ strain $\mathrm{Cb}-527$ on LB medium), Nos. 4, 5, and 6 (Bt strain Gi-466 on TYGG, TYGS, and LB media, respectively), no significant differences in the two parameters (survival rate and ALE) from the corresponding indicators in the control (without preparation) were revealed.

$B t$ strains that exhibited a pronounced antiviral activity were deposited in The Collection of Bacteria, Bacteriophages, and Fungi of State Research Center of Virology and Biotechnology Vector for further development as preventive and therapeutic antiviral drugs.

The work was carried out within the framework of the Federal Service for Surveillance on Consumer Rights Protection and Human Wellbeing sectorial research program for 2016-2020 (GZ 14/18 Study of Microbial Biodiversity in Atmospheric Aerosols).

\section{REFERENCES}

1. Andreeva IS, Mazurkova NA, Mokrushina OS, Puchkova LI, Zakabunin AI. Bacillus thuringiensis strains secreting metabolites inhibit the replication of human influenza virus A/ Aichi/2/68 (H3N2) and avian influenza virus A/chicken/Kurgan/05/2005. Mezhdunarod. Issled. Zh. 2013;(7-1):70-71. Russian.

2. Andreeva IS, Zakabunin AI. The study of extracellular nucleolytic enzymes of bacillus thuringiensis strains with the zymographic method. Colloquium-journal. 2017;(2):7-14. Russian.

3. Gribencha SV, Potseluyeva LA, Barinsky LF, Deyev SM, Balandin TG, Leshchinskaya IB. Antiviral activity of Bacillus intermedius RNAase in guinea pigs and rabbits infected with outdoor rabies virus. Vopr. Virusol. 2006;51(5):41-44. Russian.

4. Zelenikhin PV, Gorbunova AS, Makeeva AV, Ilinskaya ON, Beuerlein K. Binase-Induced Changes of Tumor Cell Membranes. Moscow Univ. Biol. Sci. Bull. 2018;73(1):7-12.

5. Ilinskaya ON, Shah Mahmud R. Ribonucleases as antiviral agents. Mol. Biol. 2014;48(5):615-623.

6. Khalafyan AA. Statistica 6.0. Data Statistical Analysis. Moscow, 2010. Russian.

7. Shah Mahmud R, Ilinskaya ON. Antiviral Activity of Binase against the Pandemic Influenza A (H1N1) Virus. Acta Naturae. 2013;5(4):44-51.

8. Shulga AA, Kirpichnikov MP, Znamenskaya LV, Morozova OV, Leshchinskaya IB. Ribonuclease from Bacillus thuringiensis var. subtoxicus: gene structure and regulation of biosynthesis. Russ. J. Bioorgan. Chem. 2000;26(9):677-678.

9. Deutscher MP, Li Z. Exoribonucleases and their multiple roles in RNA metabolism. Prog. Nucleic Acid Res. Mol. Biol. 2001;66:67-105.

10. Hartley RW. Barnase and barstar. Ribonucleases. Structures and Functions. D’Alessio G, Riordan JF, eds. San Diego, 1997. P. 51-100.

11. Leland PA, Raines RT. Cancer chemotherapy — ribonucleases to the rescue. Chem. Biol. 2001;8(5):405-413.

12. Sen'kova AV, Mironova NL, Patutina OA, Mitkevich VA, Markov OV, Petrushanko IY, Burnysheva KM, Zenkova MA, Makarov AA. Ribonuclease binase decreases destructive changes of the liver and restores its regeneration potential in mouse lung carcinoma model. Biochimie. 2014;101:256-259.

13. Zhou WW, Niu TG. Purification and some properties of an extracellular ribonuclease with antiviral activity against tobacco mosaic virus from Bacillus cereus. Biotechnol. Lett. 2009;31(1):101-105.

14. Znamenskaia LV, Morozova OV, Vershinina VI, Krasnov SI, Shul'ga AA, Leshchinskaia IB. Biosynthesis of extracellular guanyl-specific ribonuclease from Bacillus circulans. Mikrobiologia. 1998;67(5):619-625. 